\title{
Perancangan Mekanisme Spoiler Dinamis
}

\author{
Ian Hardianto Siahaan ${ }^{*}$, Timothy Osmond ${ }^{2}$, Roche Alimin ${ }^{3}$ \\ 1,2,3 Program Studi Teknik Mesin, Fakultas Teknologi Industri, Universitas Kristen Petra \\ Jl. Siwalankerto 121-131, Surabaya 60236, Indonesia \\ * Penulis korespondensi; E-mail: ian@petra.ac.id
}

\begin{abstract}
ABSTRAK
Seiring dengan perkembangan teknologi yang semakin cepat, penggunaan komponen aerodinamika tipe aktif mulai banyak diterapkan pada mobil. Salah satunya adalah spoiler dinamis. Spoiler dinamis adalah suatu tipe spoiler yang memiliki sinergitas ketika mobil melakukan pengereman maupun gerakan membelok serta dapat juga bekerja secara simultan. Penelitian ini bertujuan untuk merancang mekanisme spoiler dinamis yang dapat diterapkan pada mobil dengan sudut putar pergerakan spoiler dinamis maksimal sebesar $15^{\circ}$ dari kondisi normalnya ketika mobil melakukan proses pengereman maupun proses membelok. Spoiler dinamis yang diusulkan memanfaatkan sistem elektrik dengan motor servo yang mempunyai besaran torsi $1.8 \mathrm{~N} . \mathrm{m}$ sebagai aktuatornya. Input sudut roda kemudi diteruskan menjadi pergerakan potensiometer sebagai pengatur gerakan roda kemudi sedangkan input pedal rem menggunakan mekanisme push button yang dikendalikan oleh mikrokontroler Arduino. Hasil pengujian menunjukkan bahwa ketika roda kemudi diputar sebesar $90^{\circ}$ maka sudut putar spoiler bergerak sebesar $14.7^{\circ}$ dari kondisi normalnya pada salah satu sisi. Artinya, mekanisme spoiler dinamis ini dapat berfungsi dengan baik ketika kondisi pengereman maupun membelok bahkan ketika melakukan gerakan simultan. Pada saat proses pengereman, sudut kedua bagian spoiler menjadi maksimal dan hampir mencapai $15^{0}$ sebagaimana output yang diinginkan.
\end{abstract}

Kata kunci: Spoiler dinamis; aerodinamika; Arduino.

\begin{abstract}
Along with the rapid development of technology, the use of active-type aerodynamic components is widely applied in automobiles. One of the aerodynamic components is dynamic spoiler. Dynamic spoiler is a type of spoiler that has synergy when a car is braking and turning and can also operate simultaneously. This study is aimed at designing a dynamic spoiler mechanism that can be put on car with a maximum rotation angle of dynamic spoiler movement of $15^{\circ} \mathrm{from}$ its normal condition when a car is braking or turning. The proposed dynamic spoiler employs an electrical system with a servomotor that produces a torque of 1.8 N.m as its actuator. The input of steering wheel angle is converted to the movement of potentiometer as a steering wheel movement controller while a push button mechanism that is controlled by the Arduino microcontroller is used for the input of brake pedal. The test results demonstrate that when the steering wheel rotates $90^{\circ}$ the rotation angle of the spoiler moves $14.7^{\circ}$ from its normal condition on one side. This means that this dynamic spoiler mechanism can operate well when braking or turning, even when performing simultaneous movements. In braking process, the rotation angles at two parts of the spoiler become maximum and almost reach $15^{\circ}$ as expected for the desired output.
\end{abstract}

Keywords: Dynamic spoilers; aerodynamics; Arduino.

\section{PENDAHULUAN}

Dalam perlombaan balap atau racing, kecepatan bukanlah satu-satunya faktor penentu kemenangan. Dalam hal ini, faktor lainnya yaitu kestabilan posisi mobil ketika melakukan gerakan berbelok pada kecepatan tinggi menjadi fokus yang sangat dominan sebagai kajian dalam penentu kemenangan. Oleh karena itu diperlukan traksi yang baik agar mobil tidak terlempar atau bahkan terguling akibat pengaruh dari gaya sentrifugal [1]. Kemampuan belok kendaraan atau traksi belok juga memiliki peranan penting dalam mengurangi waktu yang diselesaikan oleh pembalap untuk menempuh satu putaran lap yang dikenal dengan lapse time reduction [2]. Tidak hanya ketika berbelok, pengereman juga dapat membuat mobil tidak stabil akibat titik berat kendaraan menjadi lebih maju ke depan, dimana hal ini dapat menyebabkan roda bagian belakang kehilangan traksi [3]. 
Aerodinamika berperan penting dalam kendaraan baik di pesawat maupun mobil. Berbeda dengan pesawat yang memerlukan aerodinamika untuk mengangkat pesawat sehingga pesawat dapat terbang, mobil memerlukan gaya dorong ke bawah agar mobil tidak terangkat pada kecepatan tinggi [4]. Selain itu, aerodinamika pada mobil berperan dalam peningkatan efisiensi bahan bakar, performa, dan kestabilan kendaraan [5].

Parameter yang penting dari aerodinamika mobil adalah gaya drag dan gaya lift [6]. Gaya drag adalah gaya yang menghambat laju kendaraan yang disebabkan oleh perbedaan tekanan pada sisi depan dan belakang kendaraan. Sedangkan gaya lift adalah gaya angkat kendaraan yang disebabkan oleh perbedaan tekanan antara bagian bawah kendaraan dengan bagian atasnya. Gaya hambat mulai berpengaruh ketika kendaraan mencapai kecepatan 80 $\mathrm{km} / \mathrm{jam}$ dimana $65 \%$ daya yang dibutuhkan oleh kendaraan pada kecepatan $110 \mathrm{~km} / \mathrm{jam}$ habis untuk melampaui gaya hambat tersebut [7].

Untuk mengatasi gaya hambat maka diperlukan desain bentuk kendaraan yang streamline demikian juga komponen-komponen aerodinamikanya. Salah satu komponen aerodinamika adalah wing sebagai passive option untuk reduksi drag [8]. Wing digunakan untuk memberikan gaya tekan ke bawah (downforce) atau gaya lift negatif. Downforce merupakan hal yang sangat penting terutama pada mobil karena downforce bermanfaat untuk meningkatkan traksi ban ke jalan pada kecepatan tinggi [9]. Namun demikian, wing memiliki kekurangan yaitu dapat meningkatkan gaya hambat kendaraan. Akan tetapi, gaya hambat tersebut dapat digunakan untuk memperoleh gaya tekan ke bawah untuk meningkatkan stabilitas kendaraan [10].

Seiring dengan perkembangan teknologi yang semakin cepat, perkembangan aerodinamika tipe aktif mulai diterapkan pada mobil [11]. Aerodinamika tipe aktif ini merupakan komponen aerodinamika yang bergantung pada kondisi kendaraan, seperti: kecepatan kendaraan, sudut belok roda kemudi, temperatur mesin, pengereman, dan lain-lain. Salah satu aerodinamika tipe aktif pada mobil adalah spoiler dinamis dimana angle of attack dari spoiler dapat berubah mengikuti kondisi kendaraan. Ketika kendaraan tersebut berbelok maka secara otomatis spoiler bagian kanan dan kiri mengikuti arah belok mobil. Selain itu, spoiler tipe aktif ini juga berpengaruh pada kondisi mobil ketika mobil melakukan pengereman. Ketika mobil melakukan perlambatan, secara otomatis angle of attack dari spoiler akan berubah. Pada angle of attack dari spoiler sebesar $20^{\circ}$, kecepatan $150 \mathrm{~km} / \mathrm{jam}$ mampu mengurangi jarak pengereman sebesar $4.52 \%$ dibandingkan dengan mobil tanpa menggunakan spoiler [2].
Dalam penelitian sebelumnya, telah dilakukan perancangan mekanisme active spoiler dengan menggunakan sistem pneumatik. Mekanisme spoiler tersebut dapat membuka, menutup, dan memberikan sudut tertentu ketika melakukan pengereman [12]. Sedangkan untuk berbelok diperlukan spoiler dinamis yang dapat menyesuaikan angle of attack pada bagian kanan dan kiri dari spoiler agar diperoleh traksi yang sesuai ketika mobil berbelok pada kecepatan tinggi. Metode pergerakan roda kemudi yang dihubungkan dengan potensiometer untuk menggerakkan motor servo dapat mengikuti sudut roda kemudi untuk mengatur pergerakan spoiler ketika mobil berbelok ke kiri dan ke kanan [13].

Penelitian ini bertujuan untuk merancang dan membuat mekanisme spoiler dinamis. Pengujian gerak angle of attack dari spoiler ketika mobil berbelok maupun ketika pengereman mobil juga dilakukan dengan spoiler dinamis. Mekanisme spoiler dinamis yang dirancang dapat diaplikasikan pada mobil dan dapat berfungsi baik ketika berbelok maupun ketika proses pengereman.

\section{METODE PERANCANGAN}

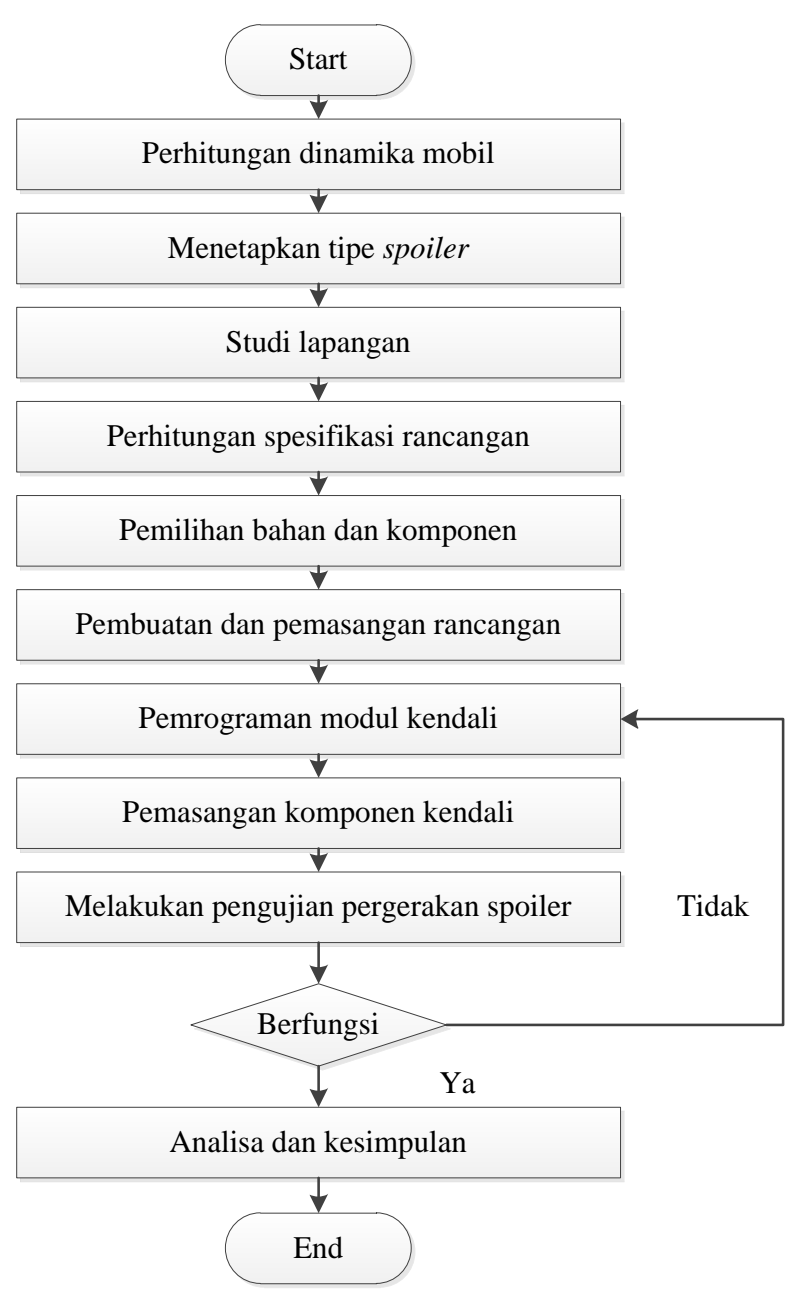

Gambar 1. Diagram alir perancangan spoiler dinamis. 
Perhitungan dinamika mobil meliputi perhitungan dimensi mobil beserta titik berat mobil. Hal ini dikaitkan dengan perpindahan titik berat ketika mobil berbelok dan ketika mobil melakukan pengereman.

Profil spoiler menggunakan NACA 23012 airfoil tool. Profil NACA 23012 dipilih karena profil tersebut sesuai dengan profil spoiler yang digunakan. Studi lapangan yang dilakukan merupakan hasil pengukuran dimensi spoiler standar sehingga peneliti dapat mengetahui penempatan spoiler dinamis beserta sensor potensiometer yang digunakan yang terhubung dengan servo motor.

Perhitungan spesifikasi rancangan meliputi perhitungan gaya-gaya yang terjadi pada spoiler termasuk penggambaran rancangan spoiler dinamis dengan bantuan software Autodesk Inventor. Pemilihan bahan dan komponen meliputi pemilihan jenis glass fiber, material spoiler bracket, servo motor, dan sambungan-sambungan yang digunakan. Setelah semua tahapan itu diselesaikan, pembuatan dan pemasangan spoiler dilakukan.

Pemrograman Arduino dan pemasangan komponen-komponen sistem elektrik perlu dilakukan agar pergerakan roda kemudi saat berbelok dan saat proses pengereman berlangsung dapat dikendalikan. Untuk memastikan apakah target sesuai dengan yang diinginkan yaitu berdasarkan pergerakan servo motor, pengujian pergerakan spoiler dan penyesuaian program dilakukan hingga pergerakan spoiler dapat berfungsi dengan baik, yaitu spoiler dapat mengikuti pergerakan roda kemudi ketika mobil berbelok maupun ketika mobil melakukan proses pengereman. Proses pengujian dilakukan dengan uji lapangan dengan menggunakan input sudut roda kemudi yang dipasang instrumen pengukur sudut roda kemudi. Dalam hal ini, busur digunakan untuk mengukur besar sudut pergerakan spoiler. Setelah itu, data pengujian diolah dan dinyatakan di dalam tabel dan grafik.

\section{HASIL DAN PEMBAHASAN}

Perhitungan rancangan spoiler meliputi perhitungan downforce dan drag force dimana Reynolds number, Re ditentukan terlebih dahulu. Setelah Reynolds number diperoleh, maka coefficient of lift, $\mathrm{Cl}$ dan coefficient of drag, $\mathrm{Cd}$ dihitung dengan menggunakan software airfoil berdasarkan profil airfoil dan aliran yang melintasi airfoil. Downforce dihitung dengan menggunakan persamaan:

$$
\text { Downforce }=\frac{1}{2} \rho V^{2} A C_{l}
$$

dimana $\rho$ adalah kerapatan udara $\left(1.185 \mathrm{~kg} / \mathrm{m}^{3}\right.$ pada suhu $\left.25^{\circ} \mathrm{C}\right), \mathrm{V}$ adalah kecepatan angin $(38.89 \mathrm{~m} / \mathrm{s}), \mathrm{A}$ adalah frontal area $\left(0.083 \mathrm{~m}^{2}\right)$, dan $\mathrm{Cl}$ adalah coefficient of lift (1.51).
Gaya yang terjadi pada spoiler juga perlu dihitung dengan menggunakan persamaan kesetimbangan gaya dan momen. Perhitungan ini bertujuan untuk mengetahui gaya yang dibutuhkan oleh servo motor untuk mengangkat spoiler tersebut.

Setelah didapatkan gaya tersebut maka kebutuhan torsi servo motor dapat dihitung dengan menggunakan persamaan torsi. Simulasi Computer Aided Design (CAD) untuk rancangan spoiler dinamis menggunakan Autodesk Inventor 2017 dengan pengaturan default. Simulasi ini bertujuan untuk mengetahui displacement terbesar pada spoiler dinamis pada kecepatan $140 \mathrm{~km} / \mathrm{jam}$ dengan angle of attack $15^{\circ}$.

Pembuatan spoiler menggunakan styrofoam sebagai cetakan, glass fiber dengan tipe woven roving sebagai fiber (serat), dan resin sebagai matriknya. Untuk bracket dan poros spoiler digunakan material aluminium, sedangkan untuk sejumlah sambungan yang ada digunakan material baja.

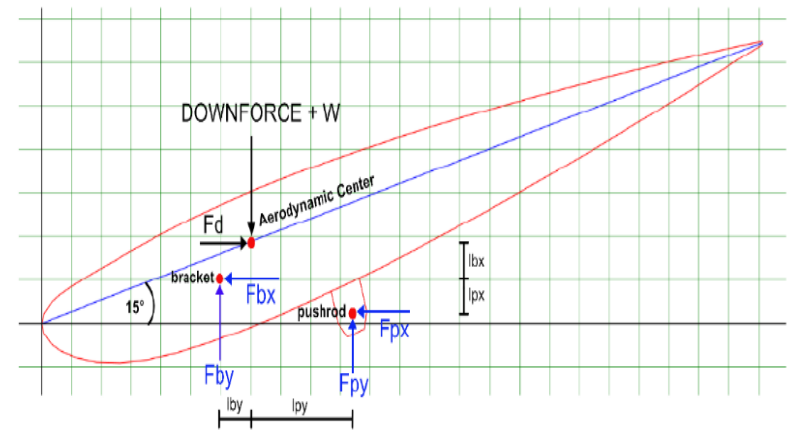

Gambar 2. Gaya yang terjadi pada spoiler

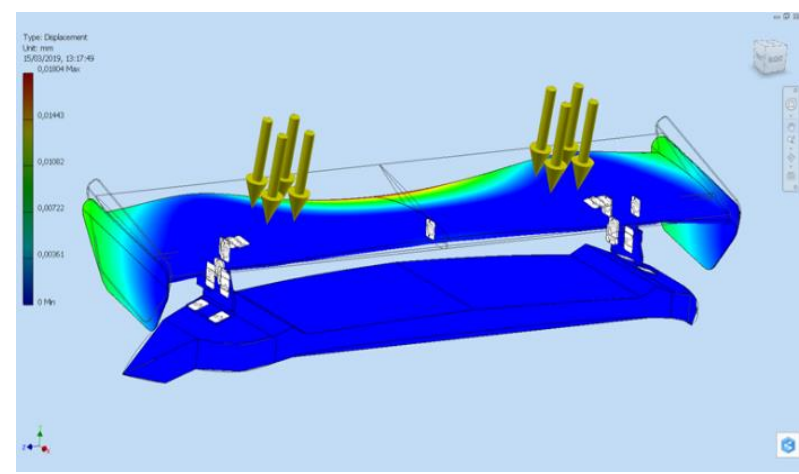

Gambar 3. Stress analysis pada spoiler dinamis

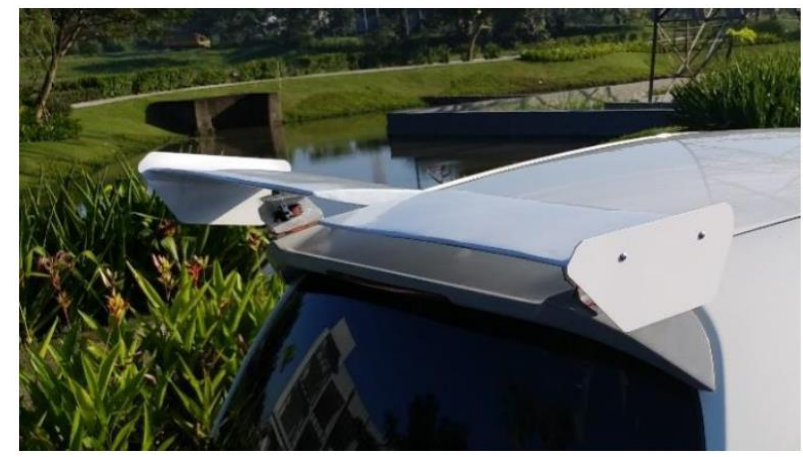

Gambar 4. Spoiler dinamis 


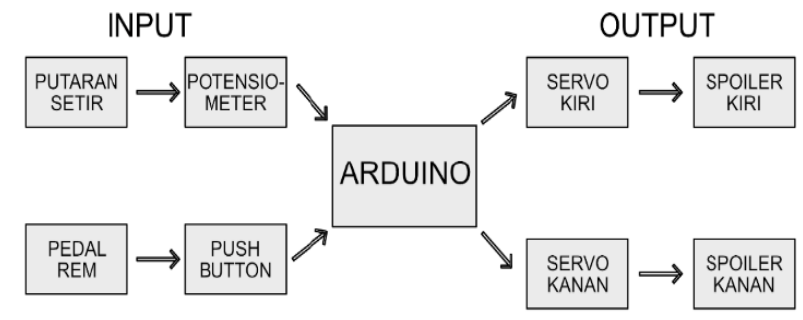

Gambar 5. Diagram mekanisme kerja spoiler dinamis

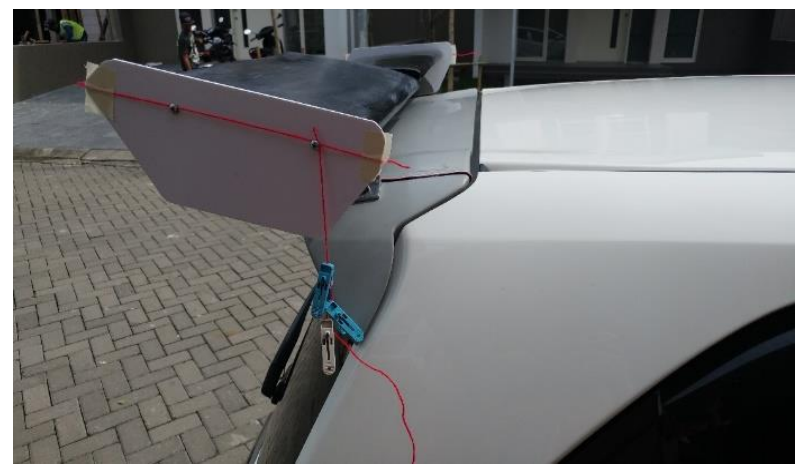

Gambar 6. Pengujian spoiler dinamis dengan pemberat

Pembuatan spoiler dinamis dan sejumlah sambungan yang ada dilakukan secara manual, sedangkan mesin milling digunakan untuk pembuatan bracket. Selanjutnya, pemasangan spoiler pada mobil standar dilakukan sebagaimana diilustrasikan dalam Gambar 4.

Spoiler dinamis menggunakan Arduino sebagai komponen yang berfungsi untuk mengendalikan gerakan spoiler. Arduino tersebut memiliki 2 input dan 2 output. Input yang pertama adalah potensiometer yang dipasang pada kolom roda kemudi sehingga potensiometer berfungsi sebagai sensor sudut roda kemudi. Input yang kedua adalah push button (tombol) yang diletakkan pada pedal rem sehingga push button berfungsi sebagai sensor untuk mendeteksi kapan mobil melakukan pengereman.

Untuk output, servo motor yang berfungsi sebagai pengubah sinyal Arduino menjadi gerakan spoiler digunakan. Sistem elektrik digunakan sehingga seluruh sistem menggunakan daya dari baterai mobil sebesar 12 Volt yang dikonversikan menjadi 5 Volt. Cara kerjanya adalah ketika roda kemudi diputar ke arah kanan maka spoiler bagian kanan akan meningkatkan sudutnya, demikian juga sebaliknya. Ketika sudut roda kemudi maksimal sebesar $90^{\circ}$, maka angle of attack maksimal sebesar $15^{\circ}$. Ketika dilakukan pengereman, maka angle of attack spoiler akan menjadi maksimal sebesar $15^{\circ}$ sehingga pengereman merupakan prioritas pertama yang kemudian diikuti dengan sudut roda kemudi. Jadi, ketika mobil dalam kondisi berbelok dan pedal rem ditekan, maka sudut spoiler bagian kiri maupun kanan akan menjadi $15^{\circ}$.
Pengujian spoiler dinamis merupakan pengujian sudut spoiler terhadap sudut roda kemudi. Sudut roda kemudi divariasi mulai dari $0^{\circ}$ sampai $90^{\circ}$ (maksimal) dengan inkremental $15^{\circ}$. Percobaan dilakukan untuk mengetahui perbedaan sudut spoiler pada bagian kiri dan kanan. Percobaan dilakukan sebanyak tiga kali untuk mendapatkan hasil yang akurat dalam upaya antisipasi pembacaan instrument pengukur yang keliru dengan alat ukur busur dan benang yang diberi pemberat.

Tabel 1. Hasil pengujian sudut

\begin{tabular}{cc|cc}
\hline \multicolumn{2}{c|}{$\begin{array}{c}\text { Sudut Roda } \\
\text { Kiri }\end{array}$} & Kanudi (Degree) & \multicolumn{2}{c}{ Spoiler (Degree) } \\
Kiri & Kanan \\
\hline 0 & 0 & 0.2 & 0.3 \\
15 & 15 & 0.7 & 3.0 \\
30 & 30 & 3.7 & 5.0 \\
45 & 45 & 4.8 & 7.7 \\
60 & 60 & 8.3 & 9.0 \\
75 & 75 & 10.7 & 11.0 \\
90 & 90 & 14.7 & 14.2 \\
\hline
\end{tabular}

Terlihat dari data tersebut adanya perbedaan antara sudut spoiler bagian kanan dan kiri. Perbedaan yang cukup besar terutama pada saat sudut roda kemudi sebesar $15^{\circ}$ dan $45^{\circ}$. Hal ini disebabkan oleh karena toleransi pengukuran (alat ukur yang dipakai), kesalahan proses manufaktur (pembuatan spoiler secara manual), dan pemasangan komponen-komponen spoiler bagian kanan dan kiri. Ketika sudut roda kemudi minimal dan maksimal maka sudut spoiler tersebut tidak jauh berbeda. Secara grafik sudut roda kemudi terhadap sudut spoiler tidaklah linear karena pergerakannya yang menggunakan link yang mengubah gerak rotasi menjadi translasi sehingga perbandingannya tidaklah linear.

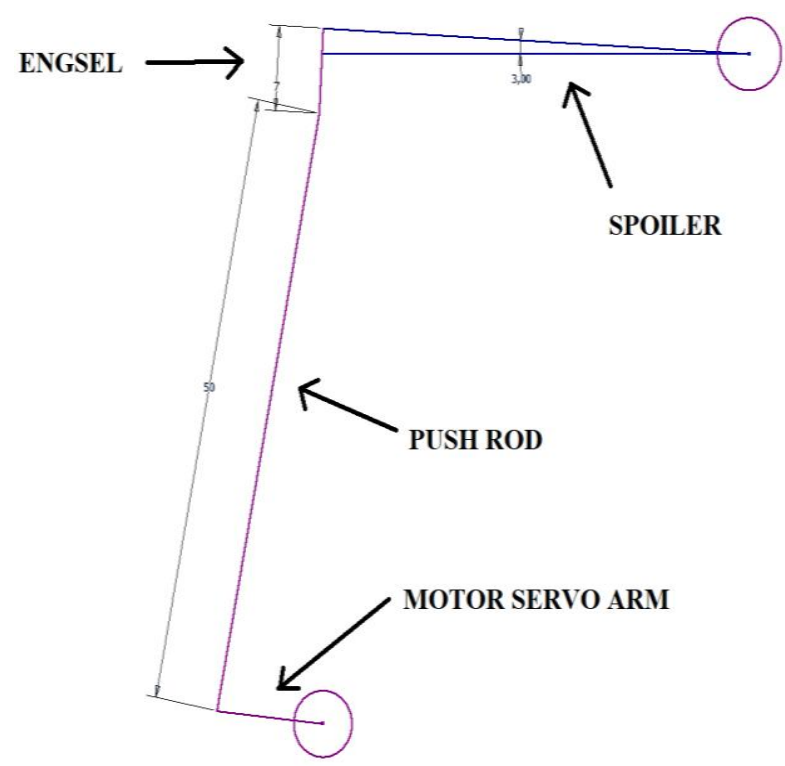

Gambar 7. Mekanisme gerak link 


\section{KESIMPULAN}

Ketika roda kemudi diputar sebesar $90^{\circ}$ maka spoiler bagian kanan memberikan sudut sebesar $14.2^{\circ}$ dan bagian kiri sebesar $14.7^{\circ}$. Ketika mobil melakukan pengereman maka kedua spoiler mencapai sudut maksimal. Kelemahan dari spoiler tersebut terdapat pada suara servo motor yang cukup keras.

Terlihat adanya sedikit perbedaan sudut antara spoiler bagian kanan dan kiri. Pada kenyataannya, sudut spoiler bagian kanan dan kiri tidak terlihat perbedaannya. Oleh karena itu, dapat disimpulkan bahwa bagian ujung spoiler, dimana area pengujian berada, berbeda dengan bagian tengah spoiler. Dapat dikatakan bahwa bentuk dari spoiler sedikit bengkok.

Pemilihan servo motor dengan torsi 1.8 N.m telah memenuhi spesifikasi spoiler dinamis dimana torsi tersebut hanya sebesar 0.103 N.m. Sehingga dapat disimpulkan bahwa spoiler dinamis dapat berfungsi dengan baik ketika mobil berbelok dan ketika mobil melakukan pengereman. Di samping itu, downforce meningkat sehingga kemampuan cengkeraman pada permukaan jalan menjadi lebih baik.

\section{DAFTAR PUSTAKA}

[1]. Seward, D., 2014, Race Car Design. 1st ed., Macmillan Education, London, the United Kingdom.

[2]. Prabhu, S., Arulvel, S., Mayakkannan, S., 2017, "CFD Analysis of Automobile Rear Dynamic Spoiler", International Journal of Scientific and Engineering Research, 8, 8, pp.1431-1435.

[3]. Jazar, R., 2008, Vehicle Dynamics: Theory and Application. 1st ed., Springer, New York, the United States of America.
[4]. Mashud, M., Ferdous, M., Omee, S. H, 2012, "Effect of spoiler position on aerodynamic characteristics of an airfoil", International Journal of Mechanical and Mechatronics Engineering, 12, 6, pp. 1-6.

[5]. Sharma, R. B., 2013, "CFD Simulation for Flow over Passenger Car Using Tail Plates for Aerodynamic Drag Reduction", OSR Journal of Mechanical and Civil Engineering, 7, 5, pp. 28-35.

[6]. Kshirsagar, V., Chopade, J. V., 2018, "Aerodynamics of High Performance Vehicles", International Research Journal of Engineering and Technology (IRJET), 5, pp. 2182-2186.

[7]. Hamut, H. S., El-Emam, R. S., Aydin, M., Dincer, I., 2014, "Effects of rear spoilers on ground vehicle aerodynamic drag", International Journal of Numerical Methods for Heat and Fluid Flow, 24, 3, pp. 627-642.

[8]. Sirenko, V., Pavlovs'ky, R., Rohatgi, U. S., 2012, "Methods of Reducing Vehicle Aerodynamic Drag", Proceeding of the ASME 2012 Summer Heat Transfer Conference, Rio Grande, Puerto Rico, the United States of America.

[9]. Bhatt, Prahar, 2015,"Dynamic Rear Car Spoiler For High Speed Turning Stability", International Journal of Mechanical and Production Engineering, 3, 2, pp. 48-49.

[10]. Cai, J., Kapoor, S., Sikder, T., He, Y., 2017, "Effects of Active Aerodynamic Wings on Handling Performance of High-Speed Vehicles", SAE Technical Paper, Detroit, Michigan, the United States of America.

[11]. Diba, F., Barari, A., Esmailzadeh, E., 2014, "Handling and safety enhancement of race cars using active aerodynamic systems", Vehicle System Dynamics, 52, 9, pp. 1171-1190.

[12]. Wijaya, J. D., 2012, "Perancangan Mekanisme Active Spoiler", Mechanova, 1.

[13]. Hodianto, Y. K., Siahaan, Ian. H, 2016, "Modifikasi Sistem Headlamp Livina dengan Pergerakan Adaptive", Mechanova, 5. 